\title{
Mucociliary Clearance of Different Respiratory Conditions: A Clinical Study
}

\author{
Juliana Souza Uzeloto ${ }^{1}$ Dionei Ramos ${ }^{1}$ Bruna Spolador de Alencar Silva ${ }^{1}$ \\ Mariana Belon Previatto de Lima ${ }^{1}$ Rebeca Nunes Silva ${ }^{1}$ Carlos Augusto Camillo ${ }^{2}$ \\ Ercy Mara Cipulo Ramos ${ }^{1}$
}

${ }^{1}$ Departament of Physiotherapy, Universidade Estadual Paulista “Júlio de Mesquita Filho", Presidente Prudente, SP, Brazil

2 Departament of Physiotherapy, Universidade Estadual de Londrina, Londrina, PR, Brazil

Address for correspondence Juliana Souza Uzeloto, MsC, Department of Physiotherapy, São Paulo State University, Rua Roberto Simonsen, 305, Presidente Prudente, São Paulo, 19060-900, Brazil

(e-mail: juliana_uzeloto@hotmail.com).

Int Arch Otorhinolaryngol 2021;25(1):e35-e40.

\begin{abstract}
Keywords

- mucociliary clearance

- saccharin

- chronic obstructive pulmonary disease

- smoking

- passive smoking
\end{abstract}

Introduction Mucociliary clearance (MCC) is the first line of defense of the pulmonary system. Mucociliary clearance impairment may lead to increased risk of respiratory infections, lung injury, pulmonary repair problems, chronic dysfunctions and progression of respiratory diseases.

Objective To characterize the MCC of active and passive smokers and individuals with chronic obstructive pulmonary disease (COPD) and compare the MCC behaviors between men and women of different age groups.

Methods Patients with COPD (current smokers and ex-smokers) and apparently healthy individuals (current smokers, passive smokers and nonsmokers) were evaluated. All of the subjects underwent lung function and MCC evaluation (saccharin transport test [STT]). Smokers (with or without COPD) were questioned about the smoking history.

Results A total of 418 individuals aged 16 to 82 years old, of both genders, were evaluated. The STT values of active and passive smokers were statistically higher than those of the control group $(p<0.01)$. Men of the control group had lower values of STT than active smokers $(9.7 \pm 7.1$ and $15.4 \pm 10.1$ minute, respectively, $p<0.01)$. In addition, higher MCC velocity was observed in women that are current smokers (11.7 \pm 6.8 minute) compared with men $(15.4 \pm 10.1$ minute) in this group $(p=0.01)$. Among the younger age groups $(<50$ years old), only passive smokers presented higher STT in relation to the control group.

Conclusion Passive and active smoking are factors that influence negatively the MCC, and passive smokers may present losses of this mechanism at a younger age. Additionally, male smokers present worse MCC than male nonsmokers. received

July 22, 2019

accepted

November 11, 2019

published online

April 24, 2020
DOI https://doi.org/ 10.1055/s-0039-3402495. ISSN 1809-9777. (c) 2020. Fundação Otorrinolaringologia. All rights reserved.

This is an open access article published by Thieme under the terms of the Creative Commons Attribution-NonDerivative-NonCommercial-License, permitting copying and reproduction so long as the original work is given appropriate credit. Contents may not be used for commercial purposes, or adapted, remixed, transformed or built upon. (https://creativecommons.org/ licenses/by-nc-nd/4.0/)

Thieme Revinter Publicações Ltda., Rua do Matoso 170, Rio de Janeiro, RJ, CEP 20270-135, Brazil 


\section{Introduction}

The human airway is lined by a ciliated cylindrical pseudostratified epithelium and a layer of mucus that is produced by submucosal glands and goblet cells scattered over the epithelium. ${ }^{1}$ This integrated system of cilia and mucus characterizes the mucociliary clearance (MCC), the first line of defense of the pulmonary system.

Mucociliary clearance captures harmful particles, pathogens and toxins in the mucus layer, and removes them from the airways by the ciliary beat. Thus, disorders that affect mucus quantity, quality and/or ciliary beat may lead to impaired MCC and ultimately to obstruction and inflammation of small airways, increased risk of respiratory infections, lung injuries, lung repair problems, chronic dysfunctions and progression of respiratory diseases. ${ }^{2}$

Age and gender are factors directly related to MCC. ${ }^{3-5}$ Studies show an inverse relationship between MCC and age, which may predispose the elderly to respiratory infections. ${ }^{4-8}$ Regarding gender, some studies report that women have a better MCC than men, perhaps due to anatomical differences in which women have shorter bronchi. ${ }^{7,9-11}$ Yet, some conditions may change the frequency of ciliary beating in MCC, such as exposure to tobacco smoke ${ }^{12}$ and environmental pollution, ${ }^{4}$ as well as respiratory tract disorders such as chronic obstructive pulmonary disease (COPD).$^{13}$ The thousands of toxic substances contained in cigarette smoke directly affect the ciliogenesis process in the maturation and differentiation stage. ${ }^{14}$ They also induce apoptosis, causing death of respiratory ciliated cells earlier than expected, ${ }^{15}$ and stimulate mechanically the axonemes, increasing the frequency of the ciliary beat. ${ }^{16}$ In specific conditions such as in the presence of COPD, the frequency of the ciliary beat may be impaired. ${ }^{13}$

An intact nasosinusal system is important to promote quality of life and prevent respiratory diseases. ${ }^{17} \mathrm{~A}$ normal MCC can represent integrity in the ciliary beat, ideal conditions of bronchial secretion and reflects on the perfect interaction between these two components. ${ }^{1,18}$ However, it is still unclear in the literature which clearance rate characterizes healthy subjects, smokers, passive smokers and patients with chronic conditions such as COPD. The present study aimed to characterize the MCC of active and passive smokers, individuals with COPD (smokers and nonsmokers) and to compare the values with a reference sample of healthy volunteers. In addition, the influence of age and gender on MCC was evaluated.

\section{Methods}

\section{Study Design}

In the present study, participants of both genders and $>16$ years old were included if they presented any of the following conditions: 1) patients with COPD and current smokers participating in a pulmonary rehabilitation program, 2) patients with COPD and ex-smokers participating in a pulmonary rehabilitation program, 3) current smokers participating in a smoking cessation program, 4) passive smokers (family members of the current smokers) and 5) nonsmoking volunteers. In addition, they must have one of the following characteristics: 1) spirometry alteration post bronchodilator $\left(\mathrm{FEV}_{1} / \mathrm{FVC}<0.70\right)$ with current smoking history or; 2) spirometry alteration post bronchodilator $\left(\mathrm{FEV}_{1} / \mathrm{FVC}<0.70\right)$ with previous smoking history or; 3 ) conventional cigarette smoker $>5$ years or; 4 ) living with smokers for $>1$ year or; 5 ) have never smoked or lived with smokers.

Subjects were excluded if they presented a history of nasal trauma or surgery, deviated nasal septum, upper airway inflammatory process (self-reported) or did not understand/ cooperate with the procedures and methods of the study.

The participants were submitted to an evaluation process including: questionnaire to obtain personal data, pulmonary function test and nasal MCC assessment. Current smokers and current smokers with COPD were asked about their smoking history and, lastly, current and passive smokers were evaluated about the carbon monoxide levels in the expired air (monoximetry). All of the evaluations were performed in the morning, to avoid the influence of the circadian rhythm on MCC.

The data presented in the present study originates from other cohorts, all of which were approved by the institutional review board. (\#18/2011; \#07152212.0.0000.5402; and \#00849812.0.0000.5402).

\section{Carbon Monoxide in Exhaled air (COex) - Monoximetry}

The carbon monoxide in exhaled air (COex) levels were assessed in current and passive smokers to confirm their abstinence/exposure to cigarette smoking in the 12 hours prior to the testing. ${ }^{19}$

To conduct this evaluation, subjects were instructed to inhale deeply and remain in apnea for 15 seconds, and then perform a complete and slow expiration on the mouthpiece of the monoximeter (Micro Medical Ltda., Rochester, Kent, United Kingdom). The device measures the carbon monoxide in exhaled air in parts per million.

\section{Pulmonary Function Test - Spirometry}

Spirometry was performed to assess the pulmonary function of the subjects. The test was conducted using a portable spirometer Spirobank G (Medical International Research USA, Inc.-Waukesha, Wisconsin/USA) following the criteria to pulmonary function tests established by the Brazilian Society of Pneumology and Tisiology. ${ }^{20}$ Interpretation of data followed the guidelines of the American Thoracic Society and of the European Respiratory Society. ${ }^{21}$ Finally, results (post bronchodilator) were compared with reference values specific for the Brazilian population. ${ }^{22}$

\section{Nasal Mucociliary Clearance - Saccharin Transport Test (STT)}

The MCC was assessed in ambient temperature between 22 and $27^{\circ} \mathrm{C}$ and air humidity between 50 and $60 \%$. The participants remained seated with their heads slightly extended to $\sim 10^{\circ}$. The test was started by introducing $\sim 250 \mu \mathrm{g}$ of granulated saccharin using a plastic straw, under the visual control of the evaluator, to $\sim 2 \mathrm{~cm}$ inside the right nostril. The time from the introduction of saccharin until the first 
perception of a sweet taste in the mouth was recorded. ${ }^{23}$ Subjects were instructed to do not use medications such as anesthetics, barbiturate anesthetics, tranquilizers and antidepressants, and to avoid drinking alcoholic beverages and caffeine-based substances within a minimum of 12 hours before the STT measurement. ${ }^{4}$

\section{Data Analysis}

The data analysis was conducted using the statistical software GraphPad Prism 5 (GraphPad Software, San Diego, CA, USA). Data normality was tested by the Shapiro-Wilk test. One-way analysis of variance (ANOVA) or the Kruskal-Wallis test was used for the comparisons between the five groups as well as to compare COex values between current smokers and passive smokers (three groups). Post-hoc tests were done using either the Bonferroni or Dunn tests. The Student t-test or Mann-Whitney test was done to compare the smoking history (pack-years) and the STT values between men and women. Pearson or Spearman tests were conducted to investigate correlations. The chi-squared test was used to analyze categorical data. The significance level adopted in the present study was $5 \%$.

\section{Results}

A total of 418 subjects were evaluated and grouped according to the smoking habit, passive exposure to cigarette smoke and diagnosis of COPD. Also, to better investigate factors that could influence MCC, the individuals were regrouped according to gender and age ( $\leq 50$ and $>50$ years old).

- Table 1 shows the characterization of the sample. It is possible to observe that individuals with COPD, regardless of smoking habit, were older and presented worse lungs compared with individuals without disease.

-Fig. 1 depicts the values of STT among the five groups. Although the control group presented lower values of STT, statistically significant differences were only found between control (10.55 \pm 7.33 minutes) and current $(13.41 \pm 8.67$ minutes $)$ and passive smokers (13.72 \pm 5.87 minutes) ( $p<0.01$ for both).

- Fig. 2 describes the comparisons of STT between groups, according to gender. Statistical difference was only observed among men ( $p<0.01)$ between control ( $9.72 \pm 7.14$ minutes) and current smokers (15.45 \pm 10.15 minutes) groups. In addition, better MCC was observed in women current smokers $(11.69 \pm 6.77$ minutes) compared with men in this group (15.45 \pm 10.15 minutes) $(p=0.01)$. There were no significant differences in MCC between genders in the remaining groups.

Regarding the comparison of STT between younger and older participants, differences were observed only in younger participants between the control and passive smokers groups (-Fig. $\mathbf{3}$ ).

No significant correlations were found between STT and spirometric variables (FVC \% of prediction, $\mathrm{FEV}_{1 \%}$ of prediction and $\mathrm{FEV}_{1} / \mathrm{FVC} \%$ ). Yet, among current smokers, it was not possible to find any relation between smoking history (age at which started smoking, cigarettes per day, years of smoking or pack/years) and STT ( $\mathrm{p}>0.05)$.

\section{Discussion}

The results of the present study show that current and passive smokers present higher STT values compared with the control group. These results confirm previous evidence of studies including smaller samples that MCC efficiency is compromised in these individuals. 24,25

The optimal functioning of the respiratory defense mechanism is dependent on the integrity, number and beating of cilia, and adequate biological properties of mucus. ${ }^{26}$ However, cigarette smoke (more specifically the constituent substances - phenol, formaldehyde, acrolein and potassium cyanide) has already been described as an important harmful agent for these two components (cilia and mucus) as they are capable of causing cytological and functional modifications, resulting in the damage of the MCC, with stasis of secretion and predisposition for respiratory infections. ${ }^{27}$ This theory is strengthened by findings from previous studies, ${ }^{28,29}$ in which active and passive smokers have worse STT values (and therefore greater susceptibility to respiratory infections), and may be a consequence of the deficit in the MCC of those subjects exposed to cigarette smoking.

Longer STT was found in the group of COPD smokers. A possible explanation for this may lie on the characteristics of the cilia epithelium. Hessel et $\mathrm{al}^{30}$ described that the length of the cilia epithelium in both large and small airways of nonsmokers is bigger than the length in healthy smokers and even bigger than the length in individuals with COPD. Although the values were visually discrepant, no statistical difference was observed, possibly due to the low sample size of this group. In line with this, Ito et al observed that chronic pulmonary patients, when smokers, present higher STT compared with ex-smokers. $^{31}$

Some studies ${ }^{32,33}$ suggest that there is impairment in the MCC of patients with COPD, regardless of the use of cigarettes, mainly attributing this impairment to the decline of the ciliary beating. However, in the present study, similar transportability was observed between subjects with COPD and other groups.

In the comparative analyzes among the younger participants ( $\leq 50$ years old), only passive smokers presented higher STT than the control group. Intriguingly, this finding leads us to assume that individuals passively exposed to cigarette smoke present impairments in MCC even before active smokers. However, this result should be interpreted with caution, since the time of exposure to cigarette smoke among the passive smokers of the present study is unknown.

In the investigation of a population of young smokers (18 to 35 years old), Nicola et al ${ }^{12}$ observed that they presented lower STT when compared with nonsmokers of the same age. However, abstinence was not requested before the MCC evaluation, suggesting that this response could be associated with the protection mechanism, with acceleration of ciliary beating frequency to expel the toxic agents of cigarette smoke, demonstrating integrity of this mechanism in young smokers, as in the present study. Among the older participants ( $>50$ years old), a statistical difference $(p=0.04)$ between the groups in the STT values was observed. 


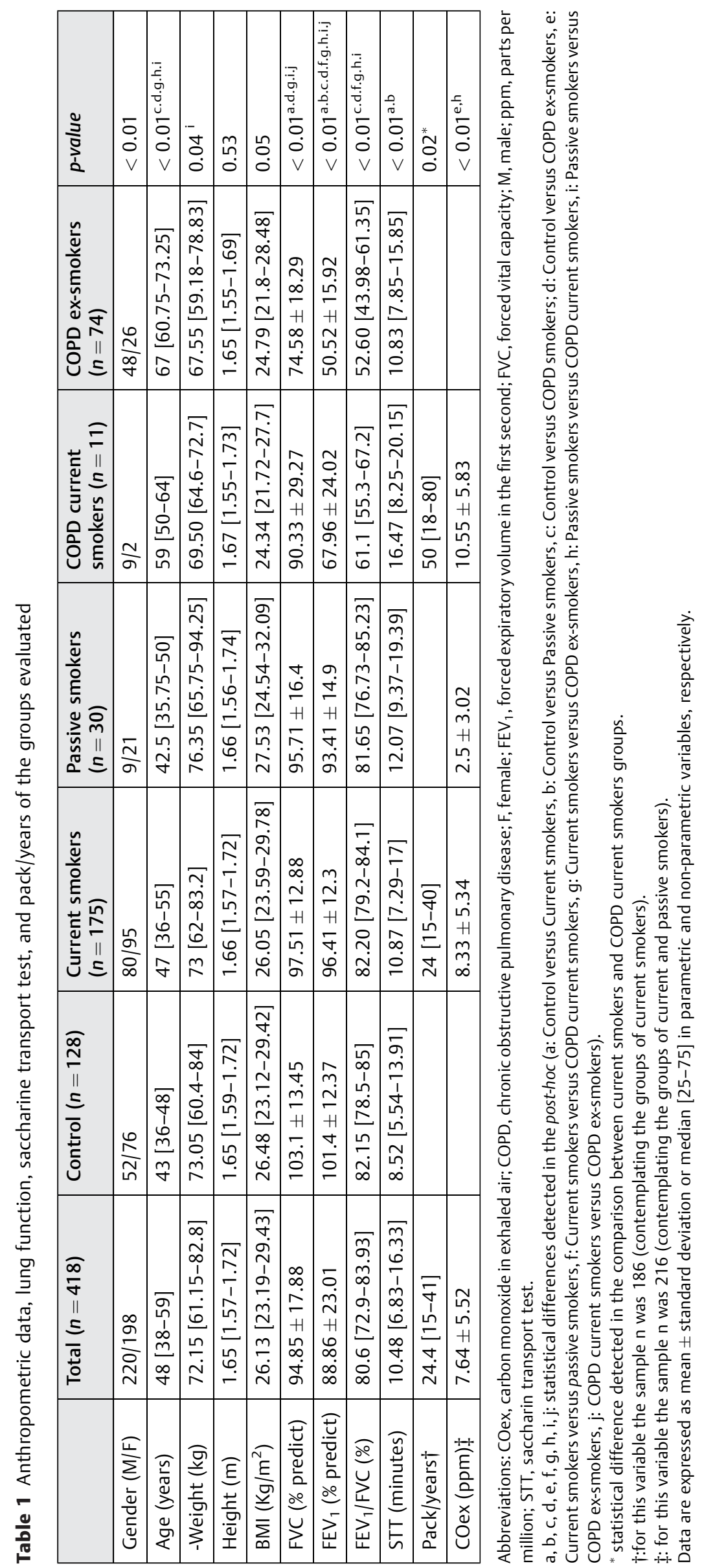




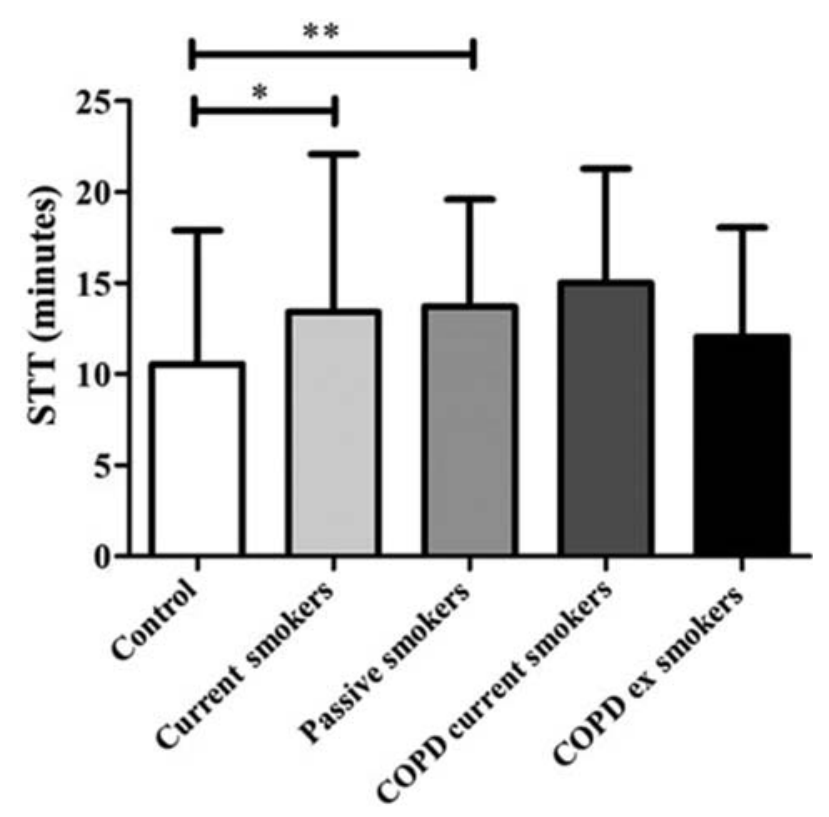

Fig. 1 Comparison of the saccharin transit test between the groups evaluated (*: difference detected in Dunn post-hoc between control and current smokers groups; ${ }^{* *}$ : difference detected in Dunn post-hoc between control and passive smokers groups); STT: saccharin transport test; COPD: chronic obstructive pulmonary disease.

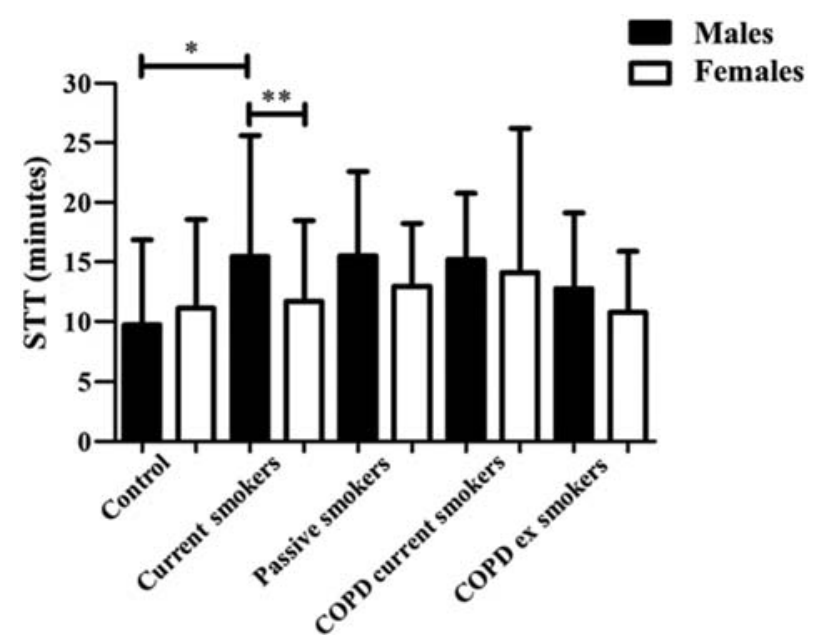

Fig. 2 Comparison of the saccharin transit test among the five groups in the different genders $\left({ }^{*}\right.$ : difference detected in Dunn post-hoc between male in the control and current smokers groups; ${ }^{* *}: p=0.01$ in the comparison between male and female current smokers); STT: saccharin transport test; COPD: chronic obstructive pulmonary disease.

Between-group differences, however, were not shown, likely due to the skewed distribution of data.

Some studies indicate that there is an inverse relation between MCC and age. ${ }^{5,9}$ However, no correlation of age and STT was observed with the general sample of the present study $(\mathrm{r}=0.09$ and $p=0.06$ ). Regarding the differences between men and women, the literature presents many divergences, even in healthy and nonsmokers individuals. Proença de Oliveira-Maul et al $^{3}$ performed STT in 79 nonsmokers and

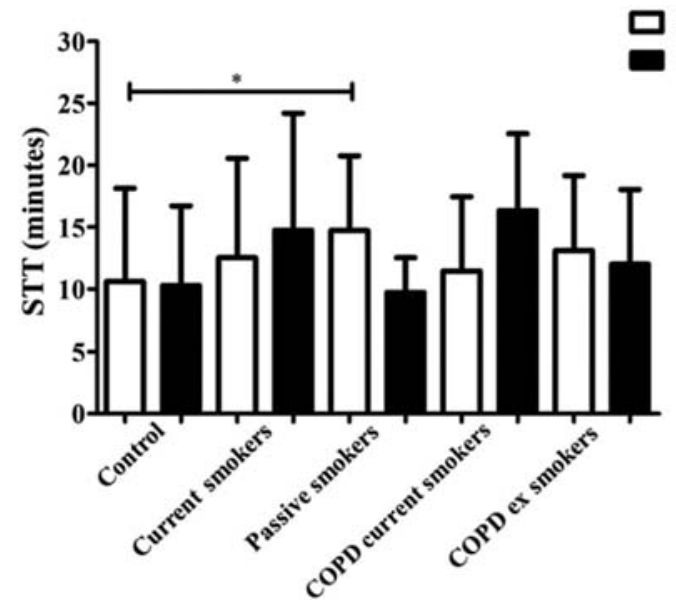

Fig. 3 Comparison of the saccharin transit test among the five groups, classified by age range $\leq$ and $>50$ years old ${ }^{*}$ : difference detected in Dunn post-hoc between the control and passive smokers $\leq 50$ years old); STT: saccharin transport test; COPD: chronic obstructive pulmonary disease.

did not find significant differences between men and women. Other authors ${ }^{7,11}$ observed better MCC in women, also healthy and nonsmokers. However, there are few studies investigating the influence of gender on MCC in other populations. Uzeloto et $\mathrm{al}^{34}$ investigated smokers and did not observe differences in the values of STT between men and women. In this study, women smokers had more efficient transport than men smokers. Yet, a comparison of the MCC by gender between the groups was done, making it possible to observe similar STT among women. However, among men, smokers showed slower MCC than the control group. These findings demonstrate a loss of this mechanism previously in men smokers.

A larger STT in the COPD smokers group (mean of 15 minutes) was observed. However, statistical differences were not observed, likely due to the low sample size of this group. The lack of quantification of passive cigarette exposure in the passive smoking group is also a limiting factor in the present study. Another limitation identified was the method used to evaluate MCC. The STT presents some disadvantages compared with rhinocintigraphy, which presents more accurate results since it calculates the exact rate of MCC by the velocity of radioactive material that is inserted into the nasal cavity and measured by a gamma camera. ${ }^{35}$ Furthermore, STT results are dependent on the gustatory sensation of the evaluated individual. Although rhinocintigraphy is a reliable and easily reproducible method, it is expensive and exposes the subject to a dose of radiation.

\section{Conclusion}

In conclusion, passive and active smoking are factors that negatively influence MCC. Passive young smokers may present impairments of this mechanism. Additionally, male smokers present worse MCC than male nonsmokers.

\section{Compliance with Ethical Standards}




\section{Ethical Approval}

All of the procedures performed in the present study involving human participants were in accordance with the ethical standards of the institutional and/or national research committee and with the 1964 Helsinki declaration and its later amendments or comparable ethical standards. The data presented in the present study originates from other cohorts, all of which were approved by the institutional review board. (\#18/2011; \#07152212.0.0000.5402; and $\# 00849812.0 .0000 .5402)$. Informed consent was obtained from all individual participants included in the study.

\section{Funding}

This study was funded by the São Paulo Research Foundation (FAPESP, in the Portuguese acronym) (grant number 2014/11970-3).

\section{Conflicts of Interests}

The authors have no conflicts of interests to declare.

\section{References}

1 Trindade SHK, de Mello Júnior JF, Mion OG, et al. Métodos de estudo do transporte mucociliar. Rev Bras Otorrinolaringol 2007; 73:704-712

2 Sears PR, Yin WN, Ostrowski LE. Continuous mucociliary transport by primary human airway epithelial cells in vitro. Am J Physiol Lung Cell Mol Physiol 2015;309(02):L99-L108

3 Proença de Oliveira-Maul J, Barbosa de Carvalho H, Goto DM, et al. Aging, diabetes, and hypertension are associated with decreased nasal mucociliary clearance. Chest 2013;143(04):1091-1097

4 Plaza Valía P, Carrión Valero F, Marín Pardo J, Bautista Rentero D, González Monte C. [Saccharin test for the study of mucociliary clearance: reference values for a Spanish population]. Arch Bronconeumol 2008;44(10):540-545

5 Paul P, Johnson P, Ramaswamy P, Ramadoss S, Geetha B, Subhashini AS. The effect of ageing on nasal mucociliary clearance in women: a pilot study. ISRN Pulmonol 2013;2013:1-5

6 Puchelle E, Zahm JM, Bertrand A. Influence of age on bronchial mucociliary transport. Scand J Respir Dis 1979;60(06):307-313

7 Armengot M, Barona R, Garín L, Basterra J. [The influence of age, sex and circadian rhythms on the nasal mucosal in the mucociliary clearance]. An Otorrinolaringol Ibero Am 1993;20(06): 581-588

8 Ho JC, Chan KN, Hu WH, et al. The effect of aging on nasal mucociliary clearance, beat frequency, and ultrastructure of respiratory cilia. Am J Respir Crit Care Med 2001;163(04): 983-988

9 Svartengren M, Falk R, Philipson K. Long-term clearance from small airways decreases with age. Eur Respir J 2005;26(04): 609-615

10 Gerrard CS, Gerrity TR, Yeates DB. The relationships of aerosol deposition, lung size, and the rate of mucociliary clearance. Arch Environ Health 1986;41(01):11-15

11 Bennett WD, Laube BL, Corcoran T, et al. Multisite comparison of mucociliary and cough clearance measures using standardized methods. J Aerosol Med Pulm Drug Deliv 2013;26(03):157-164

12 Nicola ML, Carvalho HB, Yoshida CT, et al. Young "healthy" smokers have functional and inflammatory changes in the nasal and the lower airways. Chest 2014;145(05):998-1005
13 Tilley AE, Walters MS, Shaykhiev R, Crystal RG. Cilia dysfunction in lung disease. Annu Rev Physiol 2015;77:379-406

14 Tamashiro E, Xiong G, Anselmo-Lima WT, Kreindler JL, Palmer JN, Cohen NA. Cigarette smoke exposure impairs respiratory epithelial ciliogenesis. Am J Rhinol Allergy 2009;23(02):117-122

15 Lan MY, Ho CY, Lee TC, Yang AH. Cigarette smoke extract induces cytotoxicity on human nasal epithelial cells. Am J Rhinol 2007;21 (02):218-223

16 Navarrette CR, Sisson JH, Nance E, Allen-Gipson D, Hanes J, Wyatt TA. Particulate matter in cigarette smoke increases ciliary axoneme beating through mechanical stimulation. J Aerosol Med Pulm Drug Deliv 2012;25(03):159-168

17 Borin A, Abib E Jr, Araujo CI, Martinez LL, Rodrigues H. Standardizing selection criteria in nasal medication studies. Rev Bras Otorrinolaringol (Engl Ed) 2009;75(06):872-878

18 Smith DJ, Gaffney EA, Blake JR. Modelling mucociliary clearance. Respir Physiol Neurobiol 2008;163(1-3):178-188

19 SRNT Subcommittee on Biochemical Verification. Biochemical verification of tobacco use and cessation. Nicotine Tob Res 2002;4(02):149-159

20 Sociedade Brasileira de Pneumologia e Tisiologia (SBPT). Diretrizes para testes de função pulmonar. J Pneumol 2002;28:S1-S238

21 Miller MR, Hankinson J, Brusasco V, et al; ATS/ERS Task Force. Standardisation of spirometry. Eur Respir J 2005;26(02):319-338

22 Pereira CAC, Barreto SP, Simões JG, Pereira FWL, Gerstler JG, Nakatani J.Valores de referência para espirometria em uma amostra da população brasileira adulta. J Bras Pneumol 1992;18:10-22

23 Ramos EM, Vanderlei LC, Ito JT, et al. Acute mucociliary clearance response to aerobic exercise in smokers. Respir Care 2015;60(11): 1575-1584

24 Habesoglu M, Demir K, Yumusakhuylu AC, Yilmaz AS, Oysu C. Does passive smoking have an effect on nasal mucociliary clearance? Otolaryngol Head Neck Surg 2012;147(01):152-156

25 Freire APCF, Ramos D, Leite MR, et al. Influence of time and frequency of passive smoking exposure on mucociliary clearance and the autonomic nervous system. Respir Care 2016;61(04):453-461

26 Fahy JV, Dickey BF. Airway mucus function and dysfunction. N Engl J Med 2010;363(23):2233-2247

27 Pagliuca G, Rosato C, Martellucci S, et al. Cytologic and functional alterations of nasal mucosa in smokers: temporary or permanent damage? Otolaryngol Head Neck Surg 2015;152(04):740-745

28 Petanová J. [Smoking and immunity]. . Cas Lek Cesk 2017;156 (01):6-8

29 Jayes L, Haslam PL, Gratziou CG, et al; Tobacco Control Committee of the European Respiratory Society. SmokeHaz: Systematic reviews and meta-analyses of the effects of smoking on respiratory health. Chest 2016;150(01):164-179

30 Hessel J, Heldrich J, Fuller J, et al. Intraflagellar transport gene expression associated with short cilia in smoking and COPD. PLoS One 2014;9(01):e85453

31 Ito JT, Ramos D, Lima FF, et al. Nasal mucociliary clearance in subjects with COPD after smoking cessation. Respir Care 2015;60 (03):399-405

32 Yaghi A, Dolovich MB. Airway epithelial cell cilia and obstructive lung disease. Cells 2016;5(04):e40

33 Yaghi A, Zaman A, Cox G, Dolovich MB. Ciliary beating is depressed in nasal cilia from chronic obstructive pulmonary disease subjects. Respir Med 2012;106(08):1139-1147

34 Uzeloto JS, Ramos D, Freire APCF, Christofaro DGD, Ramos EMC. Nasal mucociliary transportability of male and female smokers. Rev Bras Otorrinolaringol (Engl Ed) 2017;17:S1808-S8694

35 Di Giuda D, Galli J, Calcagni ML, et al. Rhinoscintigraphy: a simple radioisotope technique to study the mucociliary system. Clin Nucl Med 2000;25(02):127-130 